\title{
THE PHYSIOLOGY OF HYDRONEPHROSIS
}

\author{
By G. F. Murnaghan, F.R.C.S.(Ed.), F.R.C.S. \\ Lecturer, Institute of Urology, University of London
}

The term hydronephrosis denotes a condition of dilatation of the collecting system of the kidney above the level of the pelvi-ureteric junction. It acquires clinical significance by being classified according to the site and pathology of any obstruction to urine flow, but the descriptive groups so formed are unsatisfactory and not fully comprehensive. A review of the physiological processes involved in its development may help towards a better understanding of the diagnosis and management of the individual case, however this may be classified or described.

\section{Hydronephrosis without Obstruction}

Dilatation occurs in the healthy urinary tract when it is subject to the physiological demands of diuresis, raised intra-abdominal pressure, or the influence of gravity, and can be detected during pyelography if these factors are exaggerated. Campbell Begg (1946) visualized the calyces and renal pelvis as a series of spheres, and the ureter as a sequence of cylinders, and then applied to them the mathematical laws that relate to circumference and volume. It can be shown that when the circumferences of a large and of a small sphere are both shortened by the same unit of length, the reduction in the volume of the large sphere is much greater than the reduction in the small sphere. It thus follows that a dilated pelvis should expel considerably more urine by partial contraction than would the undilated organ even with complete emptying, though the actual shortening of the fibres in the muscle coat would be the same in each instance. Lengthening of the muscle fibres reduces their tonus and allows them to contract with greater efficiency, and the dilatation is thus produced as the response to the demand for more work and not as an expression of failure.

It is difficult to appreciate the sequence and purpose of the movements of the urinary tract from a series of still pyelograms, but the recent use of the X-ray Image Intensifier (Hanley, 1955) has facilitated this study by cinepyelography. Using this technique in the supine patient, the ureter is outlined as it arches over the psoas muscle, and its gentle uphill course produces a slight pelvic full- ness which can be greatly increased by tilting the patient into the Trendelenburg position. As the horizontal posture is resumed, the contractions of the pelvis recover their lost amplitude but become difficult to observe in the vertical patient because the pelvis empties very quickly and the shadow fades. Such studies suggest that gravity plays an important part in the emptying of the renal pelvis in the normal erect subject and support Campbell Begg's theory that dilatation is the normal physiological response of the healthy urinary tract to a demand for increased work, whilst the residuum of urine is a necessary part of the compensatory mechanism.

Infection can inhibit contractions by its adverse effect upon the musculature which becomes hypotonic, and mild hydronephrosis or hydrocalycosis can occur in early tuberculous or non-specific pyelonephritis as a primary dilatation and without obstruction. In these conditions there is often a quick and dramatic response to antibiotics and chemotherapy, as emphasized by Hanley (1957) in his recent review of the treatment of renal tuberculosis, and as the infection subsides the dilatation disappears.

During pregnancy there is a tendency for the renal pelves and ureters to undergo hypotonic dilatation and experimental work suggests that this is caused by a hormonal relaxation of the musculature and not by foetal pressure upon the lower ureter (Van Wagenen and Jenkins, 1939). Oestrogen levels certainly do run parallel with the degree of dilatation but this also reaches its peak during that stage of pregnancy at which urinary-tract infection commonly occurs, so that the possibility of the hydronephrosis having an infective origin cannot be excluded. Its predilection for the right side rather than the left, and the limitation of the hydroureter at the level of the pelvic brim, also implicate mechanical factors, but these are diverse and somewhat vague.

\section{Hydronephrosis with Obstruction}

When the urine flow is impeded, the usual compensatory mechanism of simple dilatation is enhanced by muscular hypertrophy in the calyces 
and pelvis. The cinepyelogram often reveals tremendous activity in the dilated tract above the obstruction and the hypertrophy bears witness to the powerful contractions that such dilated organs are capable of producing. Fatigue of the muscle, however, may eventually result from continuous overstretch and is followed by a gradual decompensation. Even slight hydronephrosis, whether ' open' or ' closed,' is prone to infection because of the residuum of urine in the dilated tract and, at any stage, sepsis may supervene and render an active, though dilated pelvis, atonic and inert. Accidental ligature of the ureter in the human subject is a well-known hazard of pelvic surgery and usually results in a urinary fistula. Renal function can, however, continue even in the absence of a fistula (Tulloch, 1952), and classical hydronephrosis then develops, though it may be several years before symptoms occur (Howarth, I949 and 1950). This chain of events is confirmed in many series of animal experiments. Complete ureteric obstruction is rarely followed by primary renal atrophy and anuria (Hepler, 1937), and the volume and nature of the fluid in the hydronephrotic sac usually produced, indicate that renal function does continue after the obstruction is established. Clearly, there must also be reabsorption from the pelvis into the circulation (pyelorenal backflow), otherwise secretion would cease when the intrapelvic pressure equalled the filtration pressure. It is well known that drugs (Tuffier, 1894) and radioopaque media (Band, r 949) are absorbed from the obstructed pelvis but the exact route taken is still not clearly understood. The calyceal fornices and veins (Hinman and Lee Brown, I924), the renal tubules (Bird and Moise, 1926; Morison, 1929), the renal veins (Fuchs, I930) and the lymphatics (Narath, 1940) have all been implicated in the mechanism of pyelorenal backflow and there is an added suggestion that extravasation into the renal substance or sinus may be an intermediate stage. In the human patient all these routes have been demonstrated during routine pyelography and at intrapelvic pressures that are as low as $25 \mathrm{~mm}$. Hg. (Ross, 1952). It seems likely that the same routes are readily available for reabsorption in clinical as well as experimental hydronephrosis, when the forceful contractions of the obstructed pelvis and calyces may raise the intrapelvic pressure above the renal secretory pressure.

The dynamics of the obstructed pelvis are accompanied by marked changes in the renal parenchyma which may be related to the diminution of the arterial and venous circulation that is produced in the kidney by the rise in intrapelvic pressure (Maatz and Krüger, 1937). Dilatation commences in the upper nephron and is followed by atrophy so that, as these changes descend to- wards the collecting ducts, cortical atrophy and medullary dilatation may occur simultaneously (Johnson, 1932). When the atrophy is complete, and shrinkage of the tubules occurs, some glomeruli may thus have a short, direct communication with the calyces. These degenerative changes have a patchy distribution which is related to the arrangement of the renal arterial tree, and those groups of glomeruli and tubules supplied by the larger terminal branches have the longest survival, but ultimately all the tubules disappear with some fibrous replacement, to leave a thinwalled sac containing only a few glomeruli. The different rates of atrophy that occur in the cortex and medulla may explain the anomalous concentrating power of the hydronephrotic kidney (Maitland, 1949), which is often belied by the appearances in intravenous pyelograms. The amount of radio-opaque agent excreted by the obstructed kidney may be appreciable but, because of dilution in the dilated pelvis and calyces, the pyelographic shadow will be considerably reduced (Keates, 1954) and this may lead to errors in the assessment of renal function.

\section{Congenital or Idiopathic Hydronephrosis}

The adverse effects of hydronephrosis upon the kidney vary with the rate of progress of the obstruction. This is usually intermittent or partial at the onset but later develops into a complete block as the pathology progresses. Such obstructive lesions as calculi or tumours frequently present clinically before the hydronephrosis is very advanced, and form a less interesting study than those indefinite lesions of the pelvi-ureteric junction that are described in the genesis of so-called congenital or idiopathic hydronephrosis. In this large group, the primary obstruction to urine flow has been attributed to stenosis, kinks, lower polar renal vessels, fibrous adhesions, high ureteropelvic insertion and neuromuscular incoordination (Fig. I).

Stenosis is the most frequent intrinsic factor present in these cases, and on histological grounds appears to have an infiammatory basis (WinsburyWhite, I925). Other studies emphasize its importance but suggest that it has a congenital origin and that any deviation from a funnel-shaped pelviureteric junction is probably pathological (Jewett, 1940). The renal pelvis could compensate for a minimal degree of narrowing at its outlet by hypertrophy of its musculature and with a physiological degree of dilatation. Infection, invited by the residuum of urine, would account for the inflammatory appearances on histological examination and, by recurrent attacks, would affect the compensation adversely and cause atonic and progressive pelvic dilatation, which may result in the 

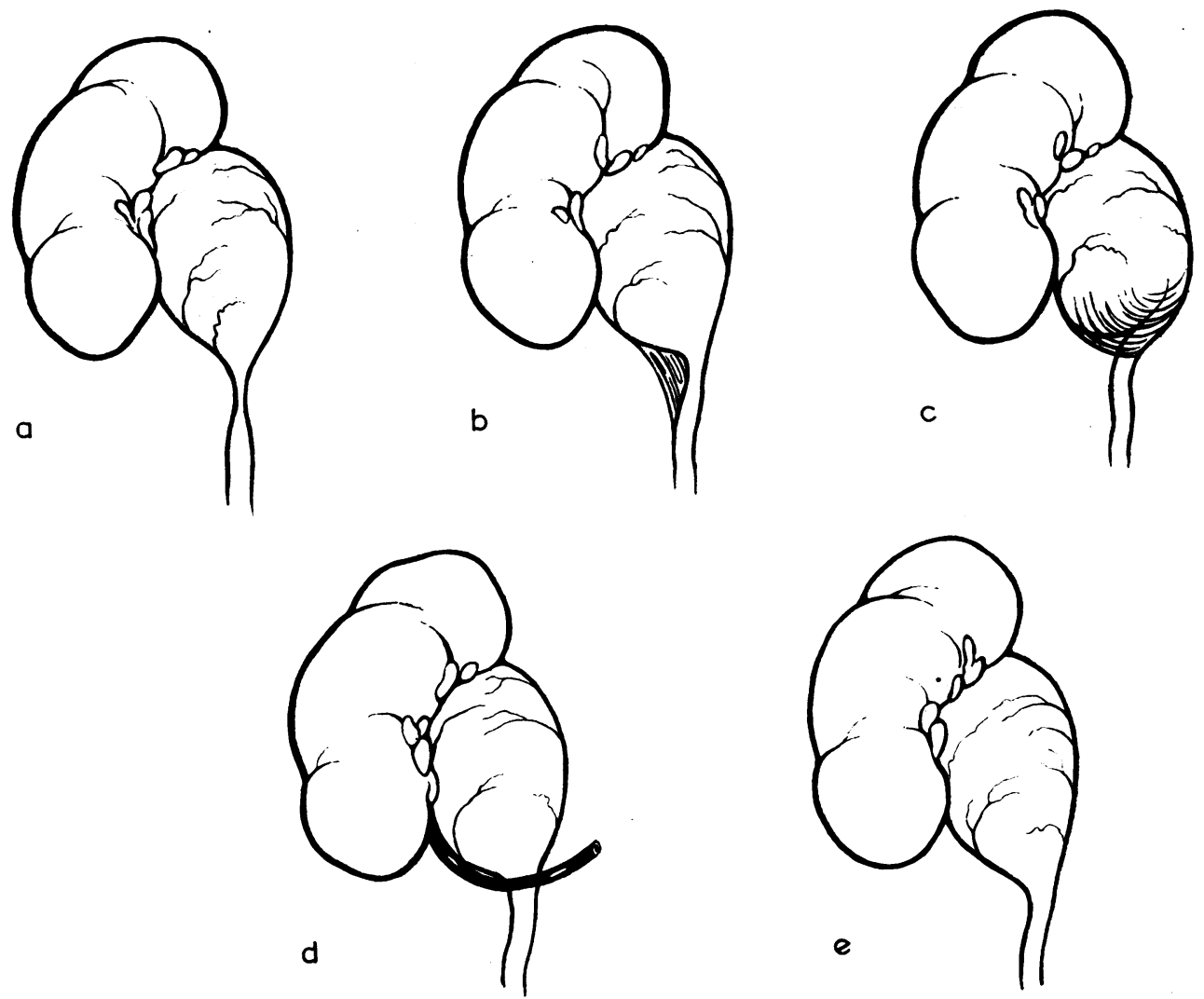

FIG. I.-Abnormalities at the pelvi-ureteric junction in congenital hydronephrosis. (b) Sail-shaped adhesions. muscular incoordination.

(c) Adventitial curtain.

(d) Lower polar renal vessel.

(a) Stenosis.

(e) Neuro-

development of high uretero-pelvic insertion, inflammatory adhesions around the junction, and a tightening of the stenosis by inflammatory change.

Some narrowing of the upper ureter occurs during normal embryological development, with the formation of folds in the mucosa and muscularis which are held together by loose transparent adventitia (Ostling, I942). In established cases of congenital hydronephrosis, adventitial folds are frequently present around the pelviureteric junction, either as a sail-shaped adhesion, extending from the pelvis to the upper ureter, or as an enfolding curtain that binds the upper ureter to the pelvis (Fig. I). Such tissue is continuous with the pelvic adventitia, and Ostling concluded that its conformity and structure corresponded so exactly to the foetal adventitial folds, as to place their derivation from the same period of development beyond any doubt. Pelvic contractions would tend to tighten these adhesions and either retract and kink the ureter or bind it to the pelvis and thus shut off the pelvic outlet.

It is difficult to decide the exact influence of lower polar renal vessels, so long referred to as aberrant, upon the genesis of congenital hydronephrosis because, in a large series of undilated renal tracts, such vessels were found to cross the region of the pelvi-ureteric junction in 6 per cent. of cases (Eisendrath and Rolnick, I942). This rather high incidence in the normal raises the suspicion that in hydronephrosis they may be merely aggravating factors and that some other intrinsic lesion impedes the urine flow. The arrangement of the renal fascia, and the tethering of the kidney by its pedicle, require the hydronephrotic pelvis to enlarge medially until it impinges upon the psoas muscle. It is then forced to move anteriorly and thus rotate the kidney about its long axis, thereby bringing any anterior lower polar vessels into closer apposition with the pelvi-ureteric junction. This would aggravate any obstruction, whatever its cause. In the stage of decompensation, when further hypotonic dilatation has occurred, the pelvis must then either extend upwards or herniate between the main renal pedicle and the lower polar vessels. In either event the vessels cross the ureter 

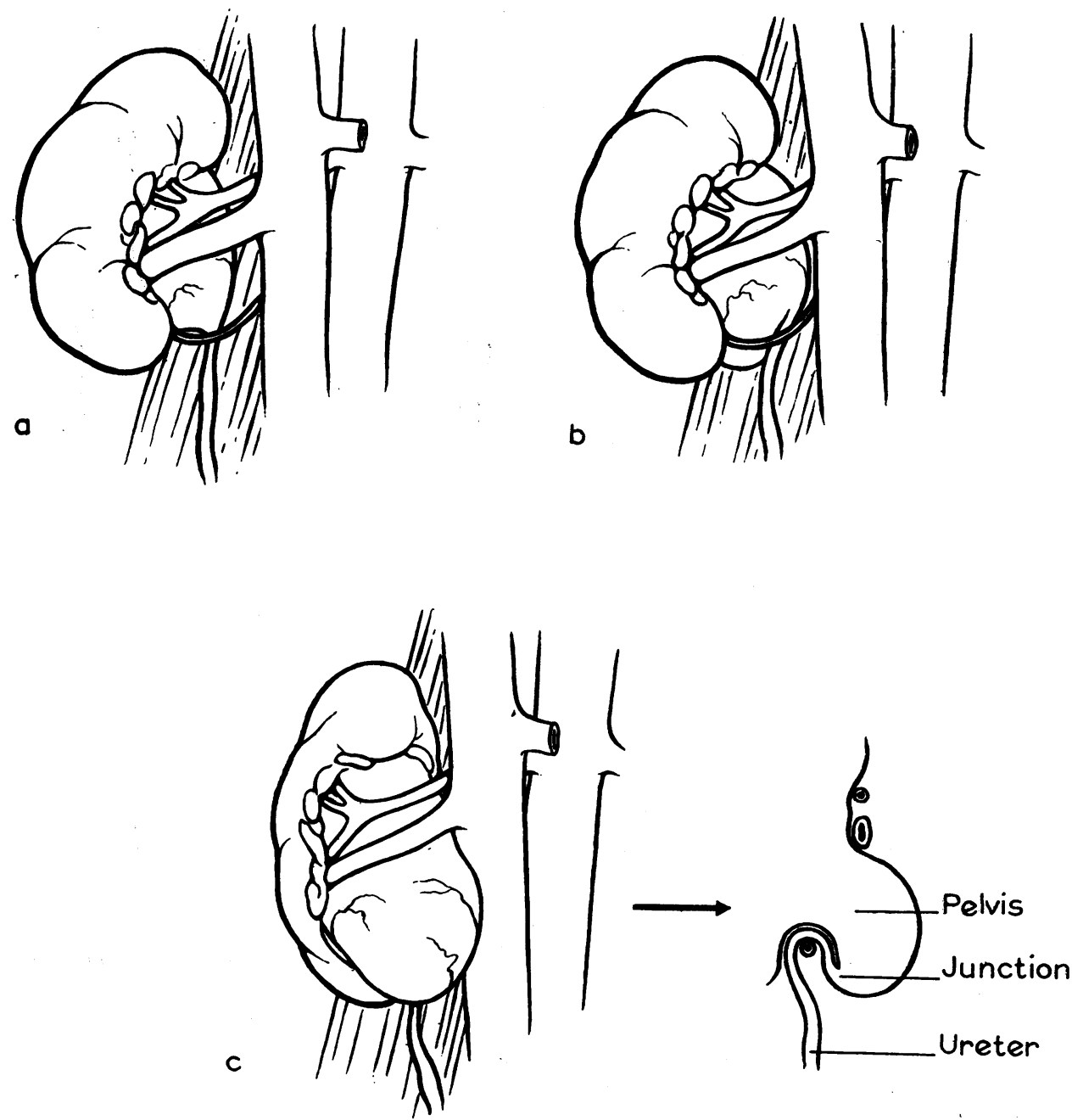

Fig. 2.-The relation of lower polar renal vessels to the pelvi-ureteric junction in congenital hydronephrosis: (a) early; (b) intermediate; (c) late.
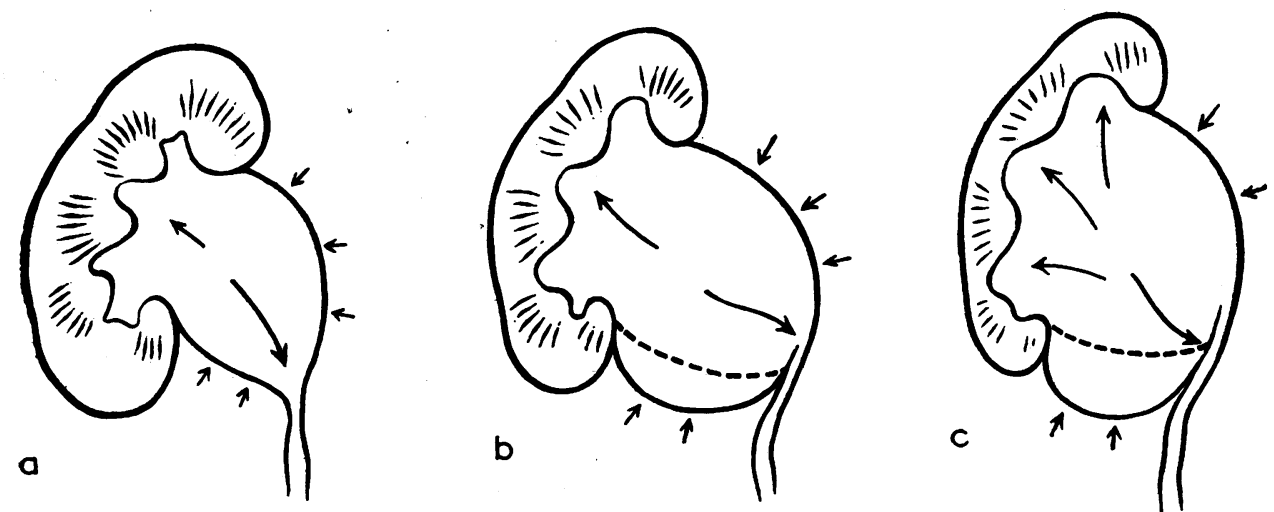

Fig. 3. - The development of complete valvular obstruction at the pelvi-ureteric outlet in advanced hydronephrosis. 
well below the pelvi-ureteric junction and bind it to the pelvis (Fig. 2). This low location does not exclude the vessels as the cause of the original obstruction at the junction itself; the regression of the pelvic dilatation which often follows the simple division of the vessels (Adams, I95I) or plication of the kidney (Hamilton Stewart, 1947) in early cases, strongly suggests that they can sometimes be the primary cause of hydronephrosis.

In the advanced case the downward sagging of the dilated pelvis places the pelvi-ureteric outlet in a relatively high position and produces a valvular obstruction to emptying that bears no direct relationship to the primary cause of the obstruction at the junction (Fig. 3). This can easily be demonstrated by manual compression at operation or rapid perfusion of the excised pelvis, which fails to empty down the ureter, though a medium-sized bougie can be passed into it easily from below.

Occasionally, hydronephrosis develops in the absence of all the intrinsic and extrinsic factors detailed above. In these cases, neuromuscular incoordination has been held responsible for the impairment of contractility, and this theory derives support from the observation that there may be a deficiency or absence of nerve fibrils passing to the muscle bundles at the pelvi-ureteric junction (Underwood, I937). Following blockade of sympathetic impulses by spinal anaesthesia, it can occasionally be seen that an inert, dilated pelvis may exhibit spontaneous rhythmical contractions, and clinical improvement in the hydronephrosis in such cases follows local sympathectomy.

These findings would appear to conflict with the thesis that the contractions of the renal pelvis and ureter are independent of the autonomic nervous system, as is suggested by a review of pharmacological investigations (Finkle and Smith, 1955) and by clinical research (Lapides, 1948). The physiological properties of ureteric muscle indicate that the contractions are initiated by its local response to stretch, and that the contractile process is then transmitted from muscle cell to muscle cell without the intervention of a nervous mechanism (Bozler, 1938). Any variation in this activity caused by drugs or nervous stimuli could be attributed to the changes that such agents produce in the intrapelvic pressure by their effect upon the blood pressure, renal blood flow, or rate of urine secretion (Dirner and Thuranskey, 1954). Denervation may raise the intrapelvic pressure in this indirect manner and elicit more powerful local stretch responses from the pelvic musculature without directly influencing the muscule fibres themselves.

Recent studies of the movements of the renal pelvis and ureter indicate that the pelvic dilatation of congenital hydronephrosis may result from an incoordination between the contractions of the pelvis and upper ureter, due to a failure of propagation of the contractile process across the pelviureteric junction (Murnaghan, 1957). This mechanism can be demonstrated both at operation and during the perfusion of excised segments and is induced by raising the intrapelvic pressure. In several of these instances, predominantly longitudinal muscle is found at the junction in place of the normal mixed muscle spirals and its distribution can be correlated with any co-existent kinks or stenosis. Such abnormal segments appear to be incapable of conducting the contractile process during distension, though their behaviour is normal at low pressure. The finding of a muscular derangement at the site of incoordinate contraction is complementary to the thesis that the contractile process is initiated and propagated by the muscle itself, though this process could also be interrupted by fatigue and infection of the muscle, or by the limitation of distension by fibrosis or the proximity of blood vessels. Such local interference with the stretch response and conductivity of the ureteric musculature produces incoordination between the contractions of the pelvis and ureter. This appears to be the basic mechanism of congenital hydronephrosis and could be induced by a muscular derangement or by any of the intrinsic or extrinsic factors previously described.

In early congenital hydronephrosis the incoordination can be demonstrated at operation by gently injecting saline into the pelvis and the area of contraction fade can be noted prior to resection of the junction. Its occurrence at high pressure explains the intermittency of such early cases and emphasizes the importance of investigating them by intravenous pyelography during an episode of pain or with reproduction of the circumstances which usually induce an attack, such as the ingestion of fluid or the adoption of any particular posture (Nesbit, 1956).

Further experiments suggest that the delay in pelvic emptying may be aggravated by a backflow of urine from the ureter into the pelvis due to retrograde contractions of the upper ureteric segment. Such contractions are initiated in the middle segment of ureter when pelvic contractions, which are the normal stimuli to 'isoperistalsis,' are either absent or are blocked at the pelviureteric junction. Such a mechanism might intermittently raise the intrapelvic pressure above the renal secretory pressure to facilitate pyelorenal backflow.

\section{Repair in Hydronephrosis}

A remarkable degree of anatomical involution, shared equally by the calyces and pelvis, often follows successful release of the obstruction in a 
hydronephrotic kidney, even of large proportions (Sargent, 1937), and a severe degree of dilatation, as seen on pyelograms, is not of itself an indication for nephrectomy. The possibilities of recovery of the renal tissue and the amount of function that may return after release of the obstruction are closely related to the condition of the renal blood supply. In the assessment of difficult cases aortography may thus be of more help than routine tests of renal function, though its use is not without hazard. If a reliable nephrogram shows occlusion of a main vessel, appreciable reduction in the number of large intrarenal vessels or absence of the smaller intrarenal vessels, then nephrectomy is probably indicated, whilst conservative surgery is more likely to be effective in those cases with a good cortical blood supply (Doss, I947).

In animal experiments, early release of total ureteric obstruction is followed by considerable recovery of renal function and repair (Hinman and Butler, 1923). However, if the contralateral kidney has been given the opportunity to undergo compensatory hypertrophy, such release is eventually followed by disuse atrophy. The recovery of the experimental hydronephrotic kidney apparently requires the stimulus of obligatory function as imposed by disease or removal of the opposite kidney. This ' renal counterbalance' is not easily defined in clinical practice and is probably rare because complete obstruction to urine flow is usually a late feature of hydronephrosis and, when such advanced cases are relieved by conservative surgery, the degree of hydronephrotic atrophy itself excludes any hope of functional recovery. The principle involved has some application in the management of established bilateral hydronephrosis, usually of the congenital variety. Surgical repair of the side most affected should be undertaken in the first instance, assuming that infection or advanced atrophy do not indicate nephrectomy (Hinman, 1946). The risk of post-operative anuria is thereby reduced, and when repair of the opposite side is carried out at a later date, the more damaged kidney will be unobstructed and more able to respond to the limitations of its fellow organ during the second operation. In this way both kidneys receive the maximum stimulation to function and to hypertrophy.

In unilateral hydronephrosis, after due consideration of infection, age and routine assessment of function, conservative release of the obstruction is justifiable, if the surgeon estimates that the treated kidney would be capable of maintaining life if disaster overtook the opposite kidney.

\section{BIBLIOGRAPHY}

ADAMS, A. W. (1951), Brit. F. Urol., 26, 3.

BAND, D. (1949), Ibid., 21, 341.

BIRD, C. E., and MOISE, T. S. (1926), F. Amer. med. Ass., 85, 663 BOZLER, E. (1938), Amer. F. Physiol., 122, 614.

CAMPBELL BEGG, R. (1946), Brit. 7 . Urol., 18, 176.

DIRNER, Z., and THURANSKEY, K. (1954), Acta. physiol. Acad. Sci. hung., 6, 385.

DOSS, A. K. (1947), Urol. cutan. Rev., 55, 134.

EISENDRATH, D. H., and ROLNICK, H. C. (1942), Urology, 4th Ed., p. 643, (Philadelphia: Lippincott).

FINKLE, A. L., and SMITH, D. R. (1955), f. Urol., 74, 312.

FUCHS, F. (1930), Dtsch. Z. Chir., 224, 353.

HAMILTON STEWART, H. (1947), Brit. ₹. Surg., 27, 506.

HANLEY, H. G. (1955), Brit. med. F., 2, 22.

HANLEY, H. G. (1957), Brit. F. Surg., 45, 10.

HEPLER, A. B. (1937), ₹. Urol., 38, 593.

HINMAN, F. (1946), Surgery, 20, 337.

HINMAN, F., and BUTLER, O. W. (I923), f. Amer. med. Ass., 81, 2021 .

HINMAN, F., and LEE BROWN, R. K. (1924), Ibid., 82, 607 HOWARTH, V. S. (1949), Med. F. Aust., 2, 678.

HOWARTH, V. S. (1950), Aust. N.Z. F. Surgery, 19, 347.

JEWETT, H. J. (1940), f. Urol., 44, 247.

JOHNSON, C. M. (1932), Ibid., 27, 279.

KEATES, P. G. (1954), f. Fac. Radiol. (Lond.), 6, 123

LAPIDES, J. (1948), $\mathcal{F}$. Urol., 59, 501.

MAATZ, R., and KRUGER, E. (1937), Z. Urol., 31, 756.

MAITLAND, A. I. L. (1949), Brit. F. Urol., 21, 334.

MORISON, D. M. (1929), Ibid., r, 30.

MURNAGHAN, G. F. (1957), Ibid., in press.

NARATH, P. A. (1940), $\mathcal{F}$. Urol., 43, 145.

NESBIT, R. M. (I956), Ibid., 75, 767.

OSTLING, K. (1942), Acta chir. scand., 86, suppl. 72.

ROSS, J. A. (1952), Brit. F. Urol., 24, 27.

SARGENT, J. C. (1937), $\mathcal{f}$. Urol., 37, 63 I.

TUFFIER, M. (1894), Ann. Mal. Org. gen.-urin., 12, 14.

TULLOCH, W. S. (1952), Brit. F. Urol., 24, 42.

UNDERWOOD, W. E. (1937), Proc. roy. Soc. Med., 30, 817.

VAN WAGENEN, G., and JENKINS, R. H. (1939), f. Urol., 42, IIO.

WINSBURY-WHITE, H. P. (1925), Brit. F. Surg., 13, 247

\section{RUTHIN CASTLE, NORTH WALES}

A Clinic for the diagnosis and treatment of Internal Diseases (except Mental or Infectious Diseases). The Clinic is provided with a staff of doctors, technicians and nurses.

The surroundings are beautiful. The climate is mild. There is central heating throughout. The annual rainfall is $\mathbf{3 0 . 5}$ inches, that is less than the average for England.

The Fees are inclusive and vary according to the room occupied.

For particulars apply to THE SECRETARY, Ruthin Castle, North Wales. 